of this kind can do good service for the many intelligent non-technical readers among the general population who wish to make some acquaintance with present-day astronomy; but on the other hand it seems to me to carry a danger for students, whether in the sixth form at school or in their undergraduate years. Unless specifically warned by someone with more experience, young men may easily get the impression that scientific research, or in particular astronomical research, is all 'cake and jam'. It is not uncommon for teachers, in other sciences as well as astronomy, to meet pupils whose imaginations have been fired by books of this kind, but whose enthusiasm tends to evaporate rather rapidly when confronted with the discipline of systematic academic learning, even before the sweat and tears of research. As a preparation for a scientific career, there is something to be said for a puritan upbringing.

This book was started some years ago and then interrupted by the War. It shows evidence, both in text and illustrations, of having been finished rather hurriedly. The post-war period so far has not given much opportunity for quiet reflexion, so desirable for the writing of a book, and perhaps this is to be blamed for the rather numerous imperfections. Then, too, for some curious reason or other, it seems to be extraordinarily difficult to write a book on popular astronomy without incurring a considerable amount of criticism from one's professional colleagues ; and, if Prof. D. H. Menzel finds himself in this respect in the distinguished company of Jeans and Eddington, it may in part be a measure of the difficulty of the task, or even of the unreasonableness of one's fellow astronomers.

To criticize in more detail : p. 5 may suggest to some readers that the majority of stars in the sky are variable. There is no good positive evidence for this, for, so far as astronomical photometry has proceeded until now, most of them seem to radiate as steadily as the sun. On p. 18 it should have been emphasized that transits of Venus are not suitable for accurate measurement of the solar parallax, as was discovered last century by numerous expensive expeditions. The important Potsdam work on granulation appears to have been ignored (p. 156). Ionized helium is not always brilliant in the flash spectrum (p. 165); it could not be detected in the low chromosphere at the 1940 eclipse. Ergs have been written for calories at the foot of p. 230. The statement (p. 277) that "The need for special photographic and spectrographic studies, at time of eclipse, is diminishing", cannot be accepted without qualification. The work of the past ten or fifteen years has raised important new questions, especially about the corona, which can be answered only by eclipse observations. There is some unnecessary repetition; for example, narrowband filters are discussed on p. 146 and again on $p$. 195. More could have been written on such matters as solar radio noise, and less on such subjects as uranium-235 and the atom bomb.

The illustrations are numerous, and for the most part are good. However, the charming young lady in Fig. 17 will ruin her left eye if she continues to observe the sun as depicted. Prof. Pannekoek's friends will be glad to see his portrait in Fig. 63, but will regret that he is not mentioned in the text. There is an excessive number of eclipse photographs of the corona, no better and no worse than the majority of those published elsewhere ; that is, they show the corona as a nearly amorphous mass, whereas the most striking characteristic to the naked eye is its structure and spikiness. In this respect, two or three good drawings would have given the reader a better impression than five times their number of photographs ; 2 remark on p. 189 suggests that the author is inclined to share this view. Figs. 174-177, to illustrate the correlations between sunspot numbers and other phenomena, are unlikely to convince a sceptic.

It would be unfair, however, to suggest that blemishes of this kind are the dominant feature of the book. "Our Sun" is no substitute for the authoritative treatise on solar research so urgently needed at present, and which Prof. Menzel himself is so well qualified to write; but the non-technical reader looking for an easy introduction to the sun as we know it to-day, who has no objection to a rather flamboyant style of writing, should be able to read it with pleasure and profit. $\quad$ R. O. REDMAN

\section{CATION EXCHANGE IN SOILS}

\section{Cation Exchange in Soils}

By Prof. Walter P. Kelley. (American Chemical Society, Monograph No. 109.) Pp. xv + 144. (New York: Reinhold Publishing Corporation; London : Chapman and Hall, Ltd., 1948.) 27s. net.

HE phenomenon of base exchange in soils, or of cation exchange as it is now ealled, was first described by J. T. Way, chemist to the Royal Agricultural Society of England, in 1850, just one hundred years ago. Hence this book, by a well-known American research worker in the subject, has come most opportunely, as it forms a timely memorial to a century of progress in a subject which looked very simple to begin with, but which has given a great deal of theoretical trouble in the past. This is a particularly favourable time to review the subject for quite another reason : the phenomena can now be explained quite adequately on a semi-quantitative basis in a way that is readily intelligible to the general scientific worker, while the next stage in the theoretical development of the subject will probably be the application of statistical mechanics to put the current explanations of the. phenomena on a more quantitative basis.

Prof. W. P. Kelley has given an excellent account of the historical development of this subject. He was a leading worker in it twenty-five years ago and has been actively interested in it ever since. He has succeoded in many places in giving a clear account of many of the earlier theories and has dealt with them sympathetically, perhaps because the outlook is often rather old-fashioned. But unfortunately some of the really fundamental properties of cation exchange do not seem to have had an adequate discussion. Thus there is no explicit discussion on the conditions under which the exchange equilibrium is reversible, and this is particularly unfortunate because in the past there was very little evidence for its true reversibility.

The book deals with other subjects besides cation exchange in soils. There is a very useful chapter on methods of determining exchangeable cations in different types of soils, and short but rather uncritical chapters on the composition of the exchangeable cations in soil, on the effect of exchangeable cations on soil properties, and on methods for identifying clay minerals.
E. W. Russell 